\title{
La posición melancólica de la cámara de Xavier Dolan en "Solo el fin del mundo"
}

\author{
Solo el fin del mundo | Xavier Dolan | 2016
}

\section{Vladimir Broda y Michèle Benhaim*}

Estudiante-investigador de cine en Paris 3, Sorbonne Nouvelle

Psicoanalista, Profesora de psicopatología Clínica, Aix-Marseille Université

Recibido: 9 de diciembre 2017; aceptado: 3 de marzo 2018

\begin{abstract}
Resumen
Steve y Louis son héroes trágicos de nuestros tiempos, confrontados a la "realidad tal como es", esta enfermedad que el poeta Gérard De Nerval llama melancolía. Xavier Dolan traduce las profundidades subjetivas de estos héroes contemporáneos y nos conmociona...

Pero ¿qué es lo que agita a Steve y silencia a Louis?

Dolan propone filmar estos mecanismos de defensa frente a la violencia del mundo actual: la agitación o la muerte, el grito o el silencio; y la cámara participa de estas demostraciones, el cuadrado que Steve termina por abrir para poder respirar pero que se cierra, inexorable, y lo borroso que rodea con frecuencia la mirada de Louis que se ausentará para siempre.

Ese mundo no es nítido... Además, ¿podríamos soportar esa mirada sobre la oscuridad del mundo actual si no fuera borroso como la mirada miope que tiene la ventaja de poder proyectar en el mundo lo que no encuentra en él?
\end{abstract}

Palabras Clave: Melancolía | Contemporáneo | Solo el fin del mundo | Xavier Dolan

Just the end of the world

Abstract

Steve and Louis are tragic heroes of the present times, confronted with the "reality as it is", this illness that poet Gérard De Nerval calls melancholy. Xavier Dolan translates the subjective depths of these contemporary heroes and it upsets us... But what agitates Steve and makes Louis silent? Dolan proposes to film these defense mechanisms against the violence of the world today: agitation or death, the cry or the silence, and the camera participates in these demonstrations, the square that Steve finally opens to breathe but which closes, inexorable, and the vagueness that often surrounds Louis' gaze who will be absent forever.

This world is not clear ... moreover we could bear this look on the darkness of the world today if it was not blurred in the manner of myopic gaze that has the advantage of being able to project on the world this that he can not find it?

Key Words: Melancholia | Contemporary | Just the end of the world | Xavier Dolan

"Solo recordarán esta sonrisa”

\section{La violencia}

Solo el fin del mundo se estrenó en 2016; es una película de Xavier Dolan que adapta la obra de teatro de Jean-Luc Lagarce, con el mismo título, escrita en 1990. Esta obra cuenta un domingo (indudablemente) particular en una familia común que se desarrolla "en algún lugar, hace ya algún tiempo". Louis, de 34 años, vuelve a visitar a su familia después de 10 años de ausencia, "bue- no, 12 si no contamos aquella vez", a pesar del miedo que se apodera de él. Miedo que nos salpica de entrada, desde los primeros minutos de la película a través de un monólogo pronunciado con una voz monótona, sombría y encantadora, planteando directamente los grandes temas de lo que será ese domingo "en familia” que llega con todo: un domingo especial, un domingo de duelo, un domingo melancólico, un domingo tenebroso tanto para Louis como para su familia. Ese domingo, día del Señor, "día de la vacuidad, día mítico de las pequeñas ceremonias domésticas y de secretos conflictos familiares" para otros, es, de hecho, el domingo en que Louis, homosexual (lo

michelebenhaim3@gmail.com 
que sigue mostrará que es importante indicarlo), debe/ quiere anunciar su muerte cercana a su familia. Familia compuesta por su madre, una mujer de 61 años de quien desconocemos su nombre en la obra pero que en la película se llama Martine, por su hermano, Antoine, de 32 años, junto a su mujer, Catherine, también de 32 años y, finalmente, por Suzanne, su hermana menor de 23 años. Insistimos en los nombres de los personajes, dado que es inevitable constatar una especie de "influencia" de la religión en esta familia. Cada nombre tiene una historia relacionada con el catolicismo. La particularidad de San Louis es haber sido considerado como un santo en vida a partir de su trabajo en la resolución de conflictos bélicos $y$, sobre todo, por su gran sentido de justicia, lo que le valió el sobrenombre de "supremo justiciero"; en cuanto a San Antoine, es el nombre de varios santos cristianos que comparten la particularidad de haber sido mártir o crucificados. Pero aboquémonos a (Santa) Suzanne, la hermana de Louis y Antoine; Suzanne es una santa mártir decapitada por su fe cristiana. Esto puede parecer inocente, excepto si tomamos la posición de "mártir" proyectada en el personaje de la hermana. Esta joven de 23 años (interpretada por Léa Seydoux), vive todavía con su madre, sus brazos cubiertos de rosas increíbles, su cara marcada y víctima de cierta tendencia toxicómana. Puede ser considerada como sacrificada como Santa Suzanne. Si tomamos la definición de la palabra "mártir" que nos ofrece Paul Laugier en su película Mártires (película de 2008 en la que actúa Xavier Dolan y lleva el nombre de Antoine...), caemos en una palabra simple, conocida por todos, pero a la vez fuertemente evocadora de la posición de Suzanne en su vínculo con la situación familiar y con su familia: se trata de la posición de testigo. Testigo de la pérdida de su hermano, testigo de la destrucción de su familia, de la destrucción de su mundo, testigo de (solo) el fin del mundo [(juste) la fin du monde]... La más chica de esta familia de tres hijos - en duelo de un padre ausente ¿o fallecido? - Suzanne parece perdida entre estos hermanos. Está como afuera de ese círculo familiar, perdida por ser la más chica, perdida por ser mujer, perdida por no tener padre, perdida ¿por no tener padre? (sus dos hermanos dejaron relativamente temprano la casa familiar), perdida por quedarse sola con la madre, de tendencia depresiva e incluso melancólica, seguramente por un duelo de su marido y/o de ese hijo Louis, que se fue sin retorno dado que "existe una variedad de motivaciones, que te pertenecen, que tienen que ver solo con vos, que te empujan a salir al mundo, a no mirar atrás", motivaciones que quedarán mudas (explícitamente) a lo largo de toda la película, a pesar de algunos esbozos de explicaciones en ciertos momentos, como durante la "charla" o más precisamente el "altercado" entre los dos hermanos, Louis y Antoine, en el auto de Antoine, único momento en el que la cámara y los personajes se escapan del lugar de la reunificación, lugar donde todo debe ponerse en juego, lugar donde la revelación debe ser enunciada. Ese único momento de "libertad" tanto para los protagonistas como para los espectadores (esa sensación de escapatoria la tiene también el espectador), se transforma en pesadilla, se transforma en un encierro [buis-clos] en esta película que ya está completamente filmada a puertas cerradas [buis-clos]. De hecho, la cámara de entrada está en el auto, entre Louis y Antoine, sin dejar respirar ni un segundo al espectador ni a los dos hermanos, sabiendo, además que ese trayecto en auto es el único momento de intimidad entre los hermanos. Ese momento fraterno, que nace a priori de una buena intención de parte de Antoine -que le propone a Louis acompañarlo a comprar cigarrillos- se transforma en un cataclismo. Esa palabra fuerte y violenta representa cabalmente la escena que se desarrolla en el auto de Antoine: Louis decide ser sincero con su hermano, anunciándole que llegó al alba y que quiere ver el amanecer desde el aeropuerto para esperar así el momento oportuno para regresar [re-venir] a lo de su madre. Pero Antoine no será nada receptivo con esta idea (¿involuntariamente?) y el tono sube un nivel en los siguientes minutos. Es principalmente en esta escena en la que se constata lo que puede aparecer como un elemento esencial de la película, el muro aparentemente infranqueable que se levanta entre estos dos hermanos; barrera que no debería existir, frontera presente tanto a nivel del estilo de vida como a nivel del lenguaje. Louis, erudito, escritor de teatro se encuentra "confrontado" a este muro que los separa: Antoine, dentro de la clase obrera dado que él mismo es obrero, y Louis, que trata a toda costa de destruir este límite por el lenguaje, tentativa que acompaña toda la película. Aquí, se revela un desfasaje social entre las dos clases en las que los dos hermanos (se) inscribieron. ${ }^{1}$ Desfasaje sostenido por una observación de Antoine en una confrontación respecto al uso burlón y/o despectivo del participio presente del verbo esperar "esperando" que refleja un registro de lengua relativamente alto de Luis.

Sin embargo, y daremos a ese momento una importancia crucial, la cámara sale del auto, se ubica ahora fuera del lugar donde se desarrolla la acción.

La cámara toma une posición verdaderamente omnisciente, neutra, ubicándose al margen de la discusión 
entre Antoine y su hermano; de hecho, casi no deja oír el discurso devastador de Antoine pero, sin embargo, nos permite percibir el estado en el que los dichos de Antoine dejan a Louis, un estado de desamparo, bañado en sudor, ojeroso. Este estado fue provocado por las palabras de Antoine, y es, precisamente, esta secuencia la que induce nuestra pregunta esencial: ¿Antoine no es finalmente la verdadera víctima de este día (y del mundo por la misma ocasión)? ¿No es el único protagonista en ver lo que tiene que ver en toda esta historia? Cada palabra que sale de su boca es, sin dudas, de una precisión y una fineza casi místicas. Antoine está constantemente a la defensiva y esta posición defensiva se traduce en agresividad, por su violencia, por la confrontación incesante, pero estos excesos lo sitúan permanentemente en lo justo, lo verdadero, y es precisamente este posicionamiento el que nos importa, esta disposición de fondo más que de forma. Su sinceridad también se libera; se mantiene meticuloso, preciso sobre lo que sabe, busca ir directo a lo esencial, no quiere desviarse porque "De la gente que no dice nada, se cree que son buenos para escuchar, cuando cierro la boca es para dar el ejemplo, para que me dejen en paz". Antoine busca la paz, la calma, la tranquilidad; no es por nada que está con Catherine, una mujer relativamente insignificante en su vida, que no dice ni una palabra, está sólo para escuchar (y todavía, durante su "charla" con Louis cuando sale del baño, Louis le pregunta “¿Todo bien?” porque "no se la escuchó mucho desde hace un rato ya"), a lo que responde "Soy asi" de manera dubitativa, balbuceando y deteniéndose en cada palabra, porque saber si está "todo bien" no parece ser una pregunta que le hacen con frecuencia. Sin embargo, es también en ese momento en el que Catherine se suelta, y se abre por fin a Louis, un extraño (a pesar del (falso) lazo familiar que los une, Louis y Catherine son extraños, no se conocen), pero ¿no es en definitiva lo profundo del pensamiento de Antoine lo que enuncia? De hecho, a pesar de su dificultad para expresarse, Catherine le explica a Louis el sentimiento que tiene Antoine respecto a ella, un sentimiento de extrañeza también. Podemos preguntarnos entonces si Louis no es finalmente un extraño en su propia familia, y en el mundo también, una especie de persona marginal, que vive como le parece sin preocuparse de las consecuencias de sus actos, ni de las repercusiones que esto pueda traer (en este caso, en su familia, las repercusiones de su partida son catastróficas).

Louis sabe que se está muriendo (podemos postular que finalmente sabe que ya está muerto), su familia (con excepción de Suzanne) lo sabe también. La película se construye así como el anuncio de una condena a muerte de un preso (acá, preso de una enfermedad), pero también como un rito funesto (incluso ¿fúnebre?). Partamos de nuestra primera hipótesis, la del condenado a muerte: efectivamente, Louis, sabiendo que está por morir se queda a la espera de una muerte cercana como lo estaría un preso en el pasillo de la muerte. Inclinémonos sobre dos escenas interesantes en este punto; la de Louis fumando un cigarrillo solo afuera, así como la de la comida en familia, afuera. Esta escena donde vemos a Louis fumando afuera un cigarrillo, solo, filmada en travelling que gira, muestra su caída, su derrumbe, tanto moral como físico, este eje circular que toma la cámara resuena como una valsa, esos segundos en el exterior son el único momento de toda la película en el que la cámara se desplaza (concretamente). En efecto, es el momento en el que su alma se escapa de su cuerpo (ya muerto) como el humo que impregna y luego se escapa de los pulmones de Louis -esto parece ser beneficioso y liberador para él. Louis está solitario afuera, es el único que no está en la sombra, el único bajo la luz que viene del cielo como un ángel que sube a los cielos. Durante esta escena, el montaje nos permite ver la cara de cada personaje (casi) simultáneamente. Se realiza un primer plano sobre cada protagonista, en el que la cara cambia para todos: la cara se les endurece a todos, excepto a la madre. Antoine le anuncia a Suzanne que "Nadie entiende nada, nadie entenderá nunca nada, esa es la belleza de las cosas, ¿no?”, seguido de una frase primordial, indispensable: "De todas formas, ya casi todo está terminado". Esta frase, esta bomba que lanza Antoine en la cara sorprendida de Suzanne que replica un " $A h, \dot{z} s i$ ? ¿Por qué?" es el desencadenamiento de la cuenta regresiva, de un minutero, del detonador de una bomba que está a punto de explotar. Pero volvamos a la cara de la madre, o solo a la madre; se queda sonriente, su actitud no cambia en toda esa jorna$\mathrm{da}$, se queda de alguna manera "feliz" de ver (y solo de ver, en el nivel más básico, es decir, en el nivel de la pura visión) a su hijo: sin embargo, podemos pensar que está en una especie de desmentida [déni] de la pérdida de su hijo, incluso ya en el duelo (que rechaza haciendo como si todo estuviera bien). Esta hipótesis es interesante, sobre todo cuando se analiza la escena del baile en la cocina, en la que toda la familia está reunida, y, sobre todo, en la que toda la familia sonríe (incluso Antoine) gracias a la madre, que empuja a su hija a bailar con ella para mostrarle a Louis su coreografía de aerobics. Esta escena se parece a una comunión, a un rito religioso en el que el mundo y los problemas externos no existen, donde todo 
parece tan simple como la coreografía de la madre y de Suzanne. Podemos relacionar esta escena a la secuencia de la comida con la mesa afuera, momento en el que pensamos que por fin podremos tener un respiro, tanto para los protagonistas como para el espectador. De hecho, esa comida, la comida, la última comida de un condenado a muerte sucede afuera, en familia. El clima de la reunión es bueno, a priori, Antoine va incluso a bromear sobre una discapacitada mental; después de esta broma, la dimensión religiosa toma la delantera, esto opaca la comida, opaca uno de los raros momentos apacibles de este domingo espantoso. Sin embargo, es durante esta escena que aparece la única evocación explícita a la santidad; después de la broma de Antoine, Catherine toma la palabra, y da (al fin) su opinión (a pesar de que el tema fuese relativamente superficial) sobre los dichos de Antoine que considera desubicados. Es en ese preciso momento que Antoine la llama "Santa Catherine" (Santa Catherine, Catherine de Alejandría, virgen y mártir en el IIIer y IV ${ }^{\circ}$ siglo). Sin embargo, esta comida que empezaba de una manera relativamente apacible, con bromas y sonrisas, pronto se transforma en un arreglo de cuentas tan pronto como una nueva confrontación opone a Suzanne y a Antoine. Es en ese momento que Louis toma "la defensa" de Suzanne -a quien Antoine impide expresarseque se alza una barrera lingüística (una crisis del lenguaje tal como la evoca el prefacio de la obra): confrontación entre el lenguaje cuidado y adornado de Louis y el de Antoine, simple, básico, directo, ciertamente reducido, pero justo, solo para decir algo de un indecible Real.

La pulsión de muerte subyace Solo el fin del mundo, pero no parece ser protagonista ni una parte necesaria a la narración o a la interpretación. Sin embargo, dos escenas la exacerban: cuando Antoine y Louis están afuera, Antoine da una especie de "primer paso" frente a su hermano proponiéndole que lo acompañe a comprar cigarrillos porque "cuando fumo, ifumo!", esta frase puede querer (o quiere poder) decir todo. En tres palabras, Antoine resume para Louis toda la complejidad de la pulsión de muerte; pero Louis no es insensible a esto y es lo que hace que por una (única) vez, puede ponerse "a la altura" de su hermano, respondiéndole simplemente " $y$ abora, necesitás fumar", dicho de otra manera, "y ahora necesitás hacerte mal”. Sigue la escena de la charla en el auto entre Antoine y Louis, en la que Louis habla de Suzanne. Finalmente, habla de la primera impresión que tiene de su hermana, hermana que no conoce, que conoce solo a través de postales, por su fecha de cumpleaños y algunos otros datos de este tenor. De esta manera, Louis dice de su hermana Suzanne que "se hunde tanto, la veo agarrando la escopeta al revés y hacerse un agujero en la cabeza”. Pero acá Louis habla en lugar de Suzanne en el nombre de su propia pulsión de muerte.

La posición de Louis, niño pródigo, es reafirmada a lo largo de toda la película por la madre. En efecto, la madre no deja de asegurarle a Louis que "tiene un don" (el don del lenguaje, siempre es escuchado cuando habla), y lo hace ante Louis mismo pero también ante otros miembros de la familia. Una frase retorna bastante seguido en la película: "bizo y siempre hace lo que tenía que hacer". Según la madre, está destinado a hacer una especie de ¿deber moral, ético? De hecho, durante la charla entre Louis y su madre en la mesada de carpintero, la madre toma una posición ética que parecía serle extraña hasta ese momento y que cambia la dirección de la película. Le da por fin un consejo ¿ "materno"? Empuja a Louis a mentirle a su hermano y a su hermana, proponiéndoles a uno ir a almorzar con él un fin de semana y, a la otra, ir a pasar unos días a su casa, en la gran ciudad en la que vive, lejos de este ambiente familiar nocivo, agrega que Suzanne "tiene derecho". Este consejo parece una misión, Louis les ofrecería una suerte de herencia simbólica: la esperanza. Cuando la película comienza su última parte, el "acto final”, que arranca durante el postre, Louis saca provecho de los consejos y dichos de su madre, e invita a Suzanne a la gran ciudad, aún sabiendo que no podrá sostener su promesa y proponiéndole a Antoine continuar la discusión sin historias, diciéndole que "puede sobrevivir un fin de semana". Pero no habrá fin de semana, no habrá más fin de semana, Louis les da esperanza sabiéndose muerto, sabiéndose ya desaparecido en los próximos fines de semana, en las próximas reuniones familiares. La esperanza ya está muerta, con Louis y su enfermedad.

Es durante esta escena que entendemos que Antoine y Catherine entendieron que la cita de Louis era con la parca, es precisamente en ese momento en que nos damos cuenta de la impresionante lucidez de Antoine.

Entonces, Louis se levanta, cambia la luminosidad; era oscura, grisácea y se vuelve amarillenta, incluso celestial.

Antoine es el mensajero de la muerte de Pierre, el viejo amor de Louis... Derrumbe, ¿traumatismo?

Es en ese preciso momento que la película da un verdadero giro, toma su verdadero sentido, todo lo que precedía no era más que una introducción, una contextualización, la escena final comienza con el anuncio de Antoine a Louis, sin término medio, sin medias tintas, brutal. 
Cuando finalmente, ;innalmente!, Louis decide anunciar su partida (su muerte), Antoine cierra nuevamente la brecha que Louis acababa de abrir en él y se vuelve duro e intransigente.

De ahora en adelante, Louis está más retraído, no sabiendo qué decir, la madre está completamente en la desmentida de la pérdida de su hijo, Catherine no tiene nada para decir, Suzanne está en la incomprensión, el espectador flota y espera que todo esto termine. Respecto a Antoine, a pesar de su comportamiento intolerable, sigue todavía estando en lo cierto poniendo un fin a este domingo funesto, incluso si solo puede denunciar la impostura mediante una violencia inaudita incluso insoportable, le hace abandonar la escena, el mundo, la vida a Louis.

Solo Suzanne se queda perdida en la incomprensión; incomprensión que Antoine le hará notar de una manera extremadamente brutal, ciertamente, pero es el único en hacerlo.

Esta brutalidad, esta violencia, esta rabia que se apodera de Antoine tiene resabios de mecanismo de defensa contra el anuncio del fallecimiento de su hermano.

Ese puño en alto, ese puño obrero arruinado por las máquinas y por la actividad manual, ese puño levantado contiene toda la rabia acumulada por Antoine durante estos doce años de ausencia de Louis, ese puño quiere decir todo y nada a la vez, ese puño de una precisión, pero también de una brutalidad infinita, temblorosa, a tan solo unos centímetros de la cara de Louis, se afloja lentamente con las palabras tranquilas y suaves de la madre.

El adiós desgarrador de una madre a su hijo, una de las cosas más insoportables y más insuperables del mundo se resuelve en estas palabras duras: "estaremos mejor preparados la próxima vez".

Es importante subrayar también que todos le preguntan por qué esta visita, por qué su visita, sin que Louis pueda anunciarles la verdadera razón de su llegada. Suzanne, al principio, no comprende su visita y no deja de preguntarle sin cesar: “¿por qué estás abî?", quizás ¿para contrarrestar una mezcla de pánico y de alegría? Louis no puede responder. Pero tampoco la madre... ni, indirectamente, Antoine, desde el auto; Antoine no quiere saber, especialmente no saber.

La cámara sale otra vez del auto, pero sin intercambio de palabras entre los dos hermanos. A la hora quince de la película, Antoine resume la situación imposible: "De la gente que no dice nada, se piensa que son buenos para escuchar, cuando cierro la boca es para dar el ejemplo, para que me dejen en paz", no quiero saber, no puedo oír.

El guiño que Louis le dirige a Catherine ya no deja ninguna duda: Louis entiende que Catherine entendió, es un guiño que tiene la confianza y el espacio necesarios a este mensaje implícito: "Te dejo al cuidado de mi hermano porque ya no estoy en el mundo de los vivos".

\section{Louis}

Steve ${ }^{2}$ y Louis son héroes trágicos de nuestros tiempos, confrontados a la "realidad tal como es", esta enfermedad que el poeta Gérard De Nerval llama melancolía. Xavier Dolan traduce las profundidades subjetivas de estos héroes contemporáneos y nos conmociona...

Pero ¿qué es lo que agita a Steve y silencia a Louis?

Dolan propone filmar estos mecanismos de defensa frente a la violencia del mundo actual: la agitación o la muerte, el grito o el silencio; y la cámara participa de estas demostraciones, el cuadrado que Steve termina por abrir para poder respirar pero que se cierra, inexorable, $y$ lo borroso que rodea con frecuencia la mirada de Louis que se ausentará para siempre.

Ese mundo no es nítido... Además, ¿podríamos soportar esa mirada sobre la oscuridad del mundo actual si no fuera borroso tal como la mirada miope que tiene la ventaja de poder proyectar en el mundo lo que no encuentra en él?

Para estas dos películas, contenemos la respiración, estamos atónitos porque es ese real contemporáneo que contienen las imágenes de Dolan, y este fuera de sentido nos horroriza hasta perdernos con los personajes en una locura-ambiente excluida de lo simbólico. Además, Dolan utiliza incluso la mirada a cámara durante un instante, en primer plano sobre Louis que nos mira, como si tratara de encontrar una escapatoria. El marco en Mom$m y$ ahoga a los personajes y nos ahoga. El marco ahoga a los personajes, la ola de calor ahoga a los personajes de Solo el fin del mundo y la madre ahoga a Steve y a Kyla, personajes que se ahogan entre ellos y nosotros, nos sofocamos...

Steve y Louis no son objetos de contención y, sin embargo, solo piden eso, ser contenidos, que algo de su angustia sea contenida, que algo de su desasosiego sea contenido pero quedarán desamparados, ambos encerrados en la incomprensión materna, ese empuje a la angustia que nos "mata" tanto como ella los encierra. Cuando nada tiene el poder de contención, ningún eco resuena 
en el interior del sujeto, confrontado entonces al vacío absoluto, ese en el que, bajo nuestra mirada "cae durante la eternidad" y el mundo parece ya no interesarles; tampoco parece interesarle al espectador.

A los personajes de Steve y de Kyla, de Antoine y de Louis, añadiremos el de Rimbaud y su desgarro, Rimbaud y su ira que no deja de recordar la de Steve, Rimbaud y su silencio (poético) que nos recuerda el de Louis.

Los puntos, las trazas melancólicas que recorren nuestros héroes, pero también cada uno de los personajes de Dolan contaminan la posición de la cámara.

"Un lindo día, no creyeron más en el futuro", así evoca Gus Van Sant a los adolescentes de Éléphant... estas palabras atraviesan a Steve ya extenuado y a Louis, casi muerto ya. En el corazón, el empuje a la angustia materno es un espacio neurálgico, pero también frágil, melancólico, un espacio vacío/lleno que solo podrá ceder con el grito de Steve que se transforma en alarido en Mommy, y con el grito de Louis que se transforma en una larga queja silenciosa, a veces muda, en Solo el fin del mundo.

El alarido de Steve y el silencio demasiado ruidoso de Louis están llenos de vacío, perdidos entre el deseo y el espanto. Firman la ruptura de los sujetos con su medio: Steve está excluido del sentido y el silencio de Louis resuena como una desaparición progresiva de sí.

La madre (tanto de uno como del otro) no puede oír, no puede oír lo indecible y el padre (tanto de uno como de otro) se ausentó, partió, murió, "ya no impresiona a la familia" como diría Lacan.

\section{La imagen melancólica}

Ahí donde Louis cree que va a reencontrarse con su familia, (re)encuentra a la única desconocida para él, Catherine: paradójicamente, ahí se ubica el encuentro, con Catherine, la única que no reencuentra: cada uno reconoce en el otro su propio encierro, se reconocen, uno va a darle al otro noticias de sí mismo; es la definición del encuentro amoroso, se revelan uno (para) el otro, este encuentro es una revelación, una complicidad, un flechazo, que no se dice, no se devela y, sin embargo, transfigura a los dos personajes.

Dolan nos confronta con seres demasiado abarrotados de amor: ¿la melancolía como un exceso de amor?

Si el punto melancólico en Mommy, la imagen melancólica es la sonrisa fija de la madre y su verborragia, el punto melancólico en Solo el fin del mundo, la imagen melancólica, es la mirada apagada de Antoine, devastado de lágrimas al levantar el puño para golpear a su hermano; llora porque el diálogo es imposible y, si se arriesgara, rozaría quizás un drama mortífero. Pero, en el paroxismo de la pelea, en el momento en que el sufrimiento de Antoine es casi tan indecible como el sufrimiento de Louis, el puño levantado encuentra la mirada del otro y su cara en su fragilidad absoluta, en su miseria; la mirada frena el puño, desvía la violencia.

Louis grita de silencio: pero de un silencio pesado, pesado de replegamiento, de incomprensión, de desmentida [dénégation] materna profunda, de un silencio lleno de lo esencial: la exactitud, el pensamiento, la palabra, el pudor, la existencia y el amor.

Todos los protagonistas de Solo el fin del mundo tienen miedo, a veces están aterrados, incluso fijos en una especie de espanto: la locura del otro sumerge a cada uno y el trastorno es entonces absoluto, se escapa y uno se pierde ahí y eso se oculta...

Cada personaje es el otro de sí-mismo, alternativamente desfasado, ausente, equívoco, borrado.

Y el espectador sigue o más bien se choca indefinidamente en el movimiento perpetuo, en el umbral, y no allí donde habría sido necesario encontrarse para permitir el duelo, en el umbral de la palabra.

¿Cómo reconciliar lo irreconciliable? Las imágenes de Dolan son claras, borrosas, indefinidas, confusas. La posición de Louis es de una claridad oscura y nadie quiere ni puede levantar el velo. Por eso ahí donde Louis viene a buscar consuelo, se choca con un ruido incesante que camufla un vacío lleno de sufrimientos y de no dichos, lleno de innombrables, sin dudas... la parte innombrable que durante mucho tiempo ocultó al sida en los años 80' 90', las tinieblas y abismos de lo contemporáneo que generan su propia oscuridad, como diría Agamben.

Mostrar lo contemporáneo del sida en el cine consiste aquí en un secreto inmostrable [immontrable] y finalmente no-enunciable [inénonçable], reflejo de esta oscuridad contemporánea.

Louis flota. Su futuro no tiene fondo pero es profundo y la cara de Louis ilumina la pantalla como la única imagen de la verdad, paradójicamente, él que va a morir y ganar las tinieblas para la eternidad.

La melancolía contenida en la caricia de su mirada sobre esta familia extraña y extranjera, tan lejos, tan cercana, fascina de dulzura y de fragilidad, la verdad se confunde en ella y se pierde en nombre del amor y de las promesas al mundo. 
Ahí donde los vivientes de la película parecen resbalarse hacia la inconsistencia, Louis, el ya-casi-muerto emerge en la luz, esta estética de la incertidumbre.

Si Antoine le da la espalda a Louis durante casi toda la película es porque rechaza verlo, no así Louis, pero lo que Louis ve, lo que lee o adivina en la mirada de Antoine, como un espejo: ¿qué ve Louis? ¿Qué ve aquel que obstruye un saber sobre la muerte? Esta ausencia de respuesta va a reducirse a la lasitud extrema de Louis y, finalmente, a la lasitud, al abandono de todos.

Además, ¿qué viene a hacer Louis acá? ¿Vino para hacerse abandonar? ¿Para morir sin ataduras? Los otros renuncian a él y él renuncia a los otros y a sí mismo, pero ¿se puede amar hasta ese punto?

Lagarce, afectado de HIV, dirá "Al principio, lo que creemos... es que el resto del mundo desaparecerá con uno; que el resto del mundo podría... apagarse, hundirse y no sobrevivirme más... poder llevármelos y no ser el único".

La imagen melancólica es la mirada apagada de Antoine, es el genio de Dolan que inscribe en esa mirada las palabras de Lagarce, sin expresarlas todas: "lo lamento, estoy cansado, ya no sé por qué estoy siempre cansado, ... un hombre cansado, ... no sé cómo explicarlo... nunca estuve tan cansado en toda mi vida", "No tengo registro de que solo hayas terminado diciendo que nadie te ama".

Antoine, melancólico (?), se siente "culpable de no sentirse suficientemente desdichado", de "no haberte dicho suficientemente que te amábamos, eso debe ser no haberte amado lo suficiente", culpable de "gozar del espectáculo tranquilizador de tu sobrevida levemente prolongada", pero Antoine hubiera "querido quedarse en la oscuridad sin responder más", hubiera "podido acostarse en el suelo y no moverse más", "acusarse sin una palabra", pero, "a pesar de todo este enojo, espero que no te pase nada malo... y ya me estoy reprochando todo lo malo que te estoy haciendo hoy".

"Me agobiás. Esperás, replegado en tu dolor interior infinito del que no sabría imaginar ni siquiera el principio del principio"... y el resentimiento de Antoine se vuelve contra sí mismo.

\section{La película, paso a paso}

La primera imagen es borrosa y Dolan agota con primeros planos, recurso que utiliza inmediatamente en la película y lo repite mucho. La motivación que empuja a Louis a volver, volver "sobre mis pasos", "hacer el viaje para anunciar mi muerte", es la "ilusión de ser mi propio amo". Ilusión... Lo borroso invade la pantalla por completo, los primeros planos desmedidos, el cartel " ¿ Necesidad de hablar?”, el humo de las fábricas, todos esos elementos se unen para expresar la desilusión que va a desgarrar lentamente a Louis.

Un reloj cucú marcará el ritmo del tiempo que pasa pero que también se estira en el transcurso de esa comida del domingo que nunca termina de terminar. El tiempo pasa y no pasa al mismo tiempo. Ese domingo no cesará de no terminar y se estirará hasta interrumpirse brutalmente, porque, sin dudas, la muerte será siempre brutal, incluso cuando la esperamos.

La llegada de Louis lo deja aparecer lejos y borroso. Sin embargo, Catherine lo reconoce incluso siendo la única en no conocerlo e incluso si es su hermana menor, Suzanne, la que le salta al cuello.

Antoine, el hermano menor, está de espaldas y seguirá así. Es la elección de la cámara de Dolan que nos indica allí cuánto Antoine quisiera no estar metido para nada en este drama.

Louis y Catherine, en el corazón de su encuentro hecho de re-conocimiento no se llevan bien con los otros, están solos en el mundo, son los mismos, ¿̇os únicos en saber? ¿En detentar un saber imposible? Ese saber que Louis detenta sobre su ineludible muerte que refleja ciertamente su mirada de angustia.

Ese saber, es impensable detentarlo: es toda la verdad, es decir, insoportable.

Por eso Louis no puede decir y la familia no puede oír.

Cuando Catherine le sonríe a Louis y él no le responde con una sonrisa, ella entiende en ese momento que se va a morir y la vemos incómoda con este saber imposible. Es lo que va a unirlos durante toda la película. A ella, no le miente.

Una vez que se "re-conocieron", que hablaron de sí mismos, ella puede, de alguna manera, empezar a tutearlo pero esto cae a veces y vuelve a tratarlo de "usted".

Louis dice en voz baja "estoy acá para eso... entre otras cosas" pero Catherine no oye. Louis los quiere mucho, a todos. ¿Y ellos? ¿Lo quieren? ¿Lo admiran? ¿Lo envidian?

Plano borroso sobre Suzanne, la hermana menor.

Catherine y Suzanne se disculpan sin cesar y Louis está todo el tiempo afligido. La ola de calor sofoca a todos. Ellas se disculpan por estar y él lamenta morir.

Suzanne habla, Suzanne cuenta pero la pantalla se vuelve borrosa y Louis no oye más lo que dice su hermana. 
Suzanne fuma marihuana, pone una pantalla de humo entre ella y el mundo y formula la pregunta que nos hace suponer que ella "sabe"

- ¿Por qué estás acá?

- No sé... Nostalgia.

Catherine le ofrece a Louis un pájaro con un vaso de vino blanco (pájaro que luego reencontraremos muerto después de haberse chocado con todas las paredes de la casa, en todos los impasses de la vida, al final de la película).

Antoine todavía está de espaldas, como siempre, incluso cuando Louis trata de atrapar la mirada y la complicidad de su hermano.

La nostalgia de la infancia será representada por lo borroso de las imágenes.

Louis vomita: no se sabe si vomita su enfermedad, su familia, o este real imposible e indecible, lo real de la muerte que asume el HIV en esos años y que hace eco con ese real de la palabra imposible.

Durante una llamada, Louis explica que todavía no dijo nada "no los conozco", "no sé cómo van a reaccionar, quizás ni siquiera lloran, tengo miedo, tengo miedo de...".

¿Louis teme la indiferencia frente a la noticia de su muerte o, al contrario, quiere protegerlos de ese punto de horror? O las dos cosas... La ambivalencia.

Y Louis insiste "boy, esperaba..." pero Catherine desiste "no me diga nada a mí, dígaselo a él (Antoine)".

Con la única persona con la que Louis hubiera podido hablar es con Catherine pero Catherine no quiere saber, ciertamente demasiado frágil para cargar con esta noticia, para soportarla, ella lo remite a un imposible, que consistiría en hablar con Antoine (que justamente no quiere oír nada). Ella argumenta "no soy buena para bablar".

En realidad, nadie quiere oír lo que Louis vino a decir, y así "nadie es bueno para hablar". En ese momento, Louis mira la hora, el tiempo pasa, pronto será la hora de "partir". Sin embargo, todos sufren.

En la cabaña, la madre se sincera por fin, ya no sonríe, explica seriamente "tenemos miedo del tiempo, del tiempo que nos das... no me hago ilusiones... sé que no te quedarás mucho tiempo".

En pocas palabras, la madre le dice casi con claridad que ella sabe... Por otro lado, ¿una madre puede no saber? Esto da fuerzas a Louis que intenta entonces, una vez más, decir "quizás tenga dos, tres cosas para decirles".

No será suficiente hasta la próxima vez: la desmentida [déni] reina como amo, incluso si, de repente, la ma- dre muestra una extrema lucidez y pone a Louis como hermano mayor, en el lugar del "hombre de la casa": "no vas a volver, lo sé... creés que no te queremos, que no te entendemos, tenés razón, no te entiendo pero te amo". Quizás sea la palabra más linda que una madre puede decirle a un hijo. Y es abrumador...

“¿Por qué estás acá? A mí, podes decírmelo." Pero nadie es tan crédulo, Louis no puede hacerlo porque, en cierta forma, al dirigirle esta palabra de amor infinito, le dice al mismo tiempo que no puede oír sobre su desaparición, su ausencia, y Louis la protege, no dice nada, y, en un común acuerdo y siguiendo la línea de la desmentida [déni], la madre agrega "en cualquier caso, tenés buen semblante...”. Pero ella sabe y lo abraza, perturba$\mathrm{da}$-ahora le toca a ella- por este saber.

Es conmovedor, estamos conmovidos y es el momento que elige Louis para recordarnos que solo tiene 34 años...

La madre sigue, "tenés los ojos de tu papá” y Louis llora...

La madre no puede dejarse llevar por la desesperación porque tiene otros hijos y entonces dice: "Pienso en el futuro". Sufre, pero no pone límites.

Louis no abandona todavía su intento, es poco convincente, pero trata, le dice a Catherine "Me bubiera gustado...", pero Catherine sabe y tiene miedo de que hable. Él dice "Ya no salgo mucho" y Catherine entiende una vez más, pero se calla.

La referencia a la infancia, a la antigua casa, es una referencia al tiempo anterior a la muerte (la muerte del padre y la muerte anunciada de Louis), pero, en un movimiento defensivo compartido, todo el mundo bromea, todos, excepto Catherine... La antigua casa está abandonada y, en esta familia, nadie sabe ya qué hacer con el pasado, están todos sobrecargados a tal punto que Antoine, para burlarse de su hermano, profiere esta frase inmunda " $i$ Tengo ganas de ir a Auschwitz para masturbarme sobre la sangre seca y escribir un poema?" que no deja de ser una referencia al HIV de aquella época, en los años '80, '90.

Antoine quiere humillar a todos porque él, el obrero, es humillado (y no es la primera referencia a la lucha de clases en la obra de Dolan, la encontramos también en Mommy).

La soledad de Catherine en la pieza resuena con la absoluta soledad de Louis cuya extrema nostalgia lo lleva al altillo borroso, borroso, borroso, propicio a los flash back de escenas de amor homosexuales de su adolescencia, una especie de escena primaria fantasmática de la contaminación combinada con porros, cocaína, bongs, 
amor, sexo, droga, no falta nada, todos los ingredientes de la condena en boga de los primeros años del sida.

Catherine lo despierta y solo le pregunta “¿Cuánto tiempo?": lo equívoco de la frase muestra que no deja de comprender... Pero, ¿cómo se habla de la muerte? ¿Cómo se dice la muerte? ¿Se dice?

Antoine está solo, tan solo, y su cara revela una tristeza insondable... Seguramente piensa que su hermano no tiene derecho a "ahogarlo", a "ahogarlos", es decir, ¿volver para anunciarles la muerte? ¡Con la ausencia ya alcanzaba!

Dolan juega con lo borroso: cuando la cámara muestra las caras en primer plano de Antoine y de Louis, es uno, o el otro, nunca los dos. Las caras... de una fragilidad infinita...

Pero cuando están en el auto, o sea ya no uno frente al otro sino uno al lado del otro, Louis empieza a hablar pero Antoine sabe que va a ahogarse, morir con Louis, y entonces, grita que no quiere oír nada.

"Venir acá no es el fin del mundo" dice Louis creyendo que, paradójicamente, solo Antoine puede oír, puede entender, pero Antoine no quiere entender y le reprocha a Louis "palabras, palabras, palabras para confundirnos, para jodernos". Y Louis que responde: "Estás enfermo, Antoine", "No, el que está enfermo sos vos, Louis" (y es verdad...).

En ese momento, es Louis el que no escucha más y Antoine, el que habla, habla, habla, solo, sus palabras cubren las palabras no dichas de Louis "si hubiéramos sabido, ni siquiera habrías venido", "llenás el vacío" le dice Antoine a Louis en una enésima proyección defensiva, mientras que es él el que no deja de hablar para llenar el vacío.

Antoine insiste "No quiero saber qué hacés acá" y Antoine acelera al máximo como para morir juntos: ni uno con el otro, ni uno sin el otro.

Cada miembro de la familia le dice en algún momento a Louis que no quiere saber, como Antoine que grita "No tengo ganas de que me hables, no tengo ganas de escucharte, tengo miedo, ¿entendés?” y le anuncia la muerte de Pierre, el primer amante de Louis, el de la escena primaria, fantasmática de la contaminación...

Todos saben y todos tapan de una manera o de otra el ruido disonante e inaudible del saber sobre la muerte, incluso Catherine que tartamudea de miedo porque sabe y sabe demasiado que sabe.

Y el péndulo del cucú marca el tiempo que pasa y Louis observa el enigma del tiempo que pasa, parece no entender. Entonces Suzanne dice: "no entiendo" y Antoine tampoco entiende; Louis llora y solo Catherine entiende: Louis llora a Pierre, o sea a su doble, es decir él mismo. El tiempo pasa y Catherine está consternada, atónita, pero "de todas formas, ya casi terminó", dice Antoine.

En ese momento, Louis renuncia "tengo algo para decirles", Catherine tiene miedo, pero ya no son las palabras de Louis que empieza a mentir, son las palabras dictadas por su madre, las únicas que todos podrían oír, las palabras que los protegerían: "Voy a volver, voy a venir más seguido, lo lamento”, pero ya nadie lo cree, no quieren oír la verdad, pero tampoco las mentiras: no quieren oír nada. Esta comida no termina más, nos ahogamos, nos sofocamos y cada vez estamos menos seguros de que "todo el mundo puede sobrevivir al fin de semana"...

\section{La imagen melancólica: el instante melancólico}

"La verdad es que me tengo que ir", dice Louis, y es esta palabra equívoca, este punto de verdad, este instante de ver, el que dispara la melancolía de Antoine. Después de las mentiras ("Voy a volver"), la verdad...

A partir de este instante, el tiempo se acelera, como un pánico por ya no poder eludir este tiempo para comprender desmentido [dénié] desde el principio. "La verdad es que me tengo que ir" abre claramente el momento ${ }^{4}$ de concluir, la vacilación de Louis, clara pero no tanto, permitía hasta entonces resbalar, patinar, hundirse a veces en ese ciego instante de ver.

Suzanne y la madre entran en pánico y quieren retener a Louis, “ $¿ Y$ qué es esa cita?”; Antoine que enloqueció con "la verdad" de la partida de Louis, también decide tener una "cita", una cita con su destino, una cita con la muerte.

La madre insiste: “¿Por qué ya no estamos bien?" "Porque tengo una cita"...

La verdad de la partida, la verdad de la "cita" también; es a esta cita a la que Suzanne va a reprocharle la brutalidad, desde el fondo de su dolor de perder a este hermano que acaba de encontrar. Es la muerte la que es "brutal", no Antoine, pero Suzanne en un último momento de desmentida [déni] llora a Louis y lamenta la "brutalidad" de Antoine. "Vos no entendiste nada, no sabés nada” solo le responderá este último.

$\mathrm{Si}$ "debo partir" significa "debo morir", podríamos hacer la hipótesis de que Antoine, el hermano menor, debió "querer", inconscientemente, la muerte de Louis, demasiado brillante; y de ahí su intensa culpabilidad que haría explotar su melancolía camuflada detrás de su estado 
maníaco, su "hiperactividad"... que no deja de evocarnos la de Steve en Mommy. Y Antoine no soporta la mirada ni la cara de este hermano que sabe que va a morir...

Louis, que vino para ser consolado, consuela "No tengas miedo, Antoine"; pero el consuelo de Louis refleja la falta (imaginaria) de Antoine y estamos aquí frente a lo que llamamos la imagen melancólica de la película: la mirada devastada por las lágrimas de Antoine; el puño, lleno de marcas de golpes, levantado pero captado en lo imposible de lo real de este instante.

Es el punto de mayor paroxismo de lo insoportable que contiene esta película: nada más se sostiene, nada más contiene, ni siquiera la mentira admitida por todos, ni siquiera la desmentida [déni] admitida por todos y la mirada de la madre le dice entonces que ella sabe, las lágrimas de Suzanne le dicen entonces que ella también sabe.

Pero esta madre, como todas las madres de las películas de Dolan, se desmaya: no puede asumir este saber imposible de la muerte de su hijo, entonces, elige darse vuelta hacia el hijo vivo...

Solo Catherine se queda... pero ya es demasiado tarde, hay un tiempo para comprender, y ya estamos en esta etapa de la película, en el momento de concluir. Aquí, Louis le hace el gesto de callarse y ella sale a su vez. Todo el mundo partió, todo el mundo dejó a Louis frente a su extrema soledad.

La cámara se aleja, Louis va a partir, Louis va a morir, el reloj determina el tiempo que huye, un pájaro se choca con las paredes, con los impasses de la vida de cada uno.

La imagen es borrosa, borrosa está todavía la madre que fuma, borrosa es la ternura infinita de Louis.

Se va, lo borroso es absoluto y el pájaro murió...

Solo el fin del mundo es una película sobre la separación, sobre el secreto intransmisible: J.L. Lagarce precisa que Louis se va "sin haber osado nunca hacer todo este mal".

Solo el fin del mundo es el fin de símismo en el mundo que deja a los personajes en la depresión pero el fin del mundo completo los hace caer en la melancolía.

Este drama íntimo nos recuerda que estamos solos en la muerte, pero Louis es eterno; Dolan le ofreció esta eternidad como Antoine que nombró Louis a su propio hijo.

Lo que une a esta familia es este no saber, o mejor, este no dicho.

Este encuentro no podía ser más que un impasse, en el cual Louis/el pájaro se golpea, se destroza hasta mo- rir, porque la palabra no vale más que como palabra a ser dirigida, sino, es "la palabra o la muerte" (siguiendo a Safouan).

Si el fin de símismo en el mundo genera la captura del sujeto en una versión depresiva de su ser en el mundo, el fin del mundo lo ve caer en la melancolía y es eso lo que refleja la cara de Antoine, el hermano.

Estos hermanos, tan lejanos, tan cercanos... finalmente, ¿qué pasa en esta película?

Louis y Antoine, las dos caras de una misma humanidad, la de Rimbaud cuya búsqueda fue la de luchar contra lo trágico de la existencia, en un desgarramiento entre la vida y el pensamiento.

Louis y Antoine se funden por un instante en nuestra mirada, en una rebelión que encuentra una expresión universal y al mismo tiempo una fuente infinita de desilusión.

Al estilo de Rimbaud, este otro rebelde, cada uno a su manera tiene una mirada proyectiva sobre el mundo, que corre el riesgo de deshacer el lazo de alteridad cortándose del lenguaje, espejo de un mundo contemporáneo difractado, cínico y empobrecido del que la poesía de Rimbaud tanto como las actitudes de Antoine y Louis, critican hasta en la herida de la sociedad.

Antoine es insoportable porque todo le resulta insoportable y es este insoportable de lo trágico de la existencia que viene a anunciar el tiempo contado (el cucú) del sida, la muerte anunciada de su hermano.

A Antoine le duele la vida y Louis pierde la vida y este doble punto de sufrimiento innombrable flota en el vacío que Louis llena de silencios y que Antoine ahoga con gritos.

Lagarce o Dolan hubieran podido prestar estos versos de Rimbaud a Antoine, a quien todos le reprochan su brutalidad: "Sí, tengo los ojos cerrados a vuestra luz. Soy una bestia, un negro. (...) No entiendo las leyes, no tengo sentido moral, ;soy un bruto!"

Antoine y Louis "sin saber nada de lo que hay que saber, decididos a no hacer nada de lo que hay que hacer", están "condenado(s), desde siempre, para siempre", como Arthur.

Solo el fin del mundo es una película sobre la implacable desesperación de los hombres que saben que se vuelven locos, locos para olvidar que el mundo está ahí, insoluble, y Rimbaud dirá de sí mismo que él "no sabe nada de lo que hay que saber"...

Traducción: Noelia Luzar 
N. de la T.: En el texto original, hay un juego de palabras entre se inscribieron o están inscriptos con un paréntesis en el "se” que es la única diferencia entre estas dos expresiones [(se) sont inscrits].

2 Héroe de Mommy, película de Xavier Dolan, 2014.

3 En francés, es muy frecuente el uso del "usted” entre jóvenes, incluso de la misma familia, si no se conocen mucho.

$4 \quad$ El tiempo lógico de Lacan: el instante de ver, el tiempo para comprender, el momento de concluir. 